\title{
„Heroismus als Weg zur Transzendenz““. Metadiskursive Religionsbezüge und apokalyptische Diskurspraxis der Neuen Rechten
}

\author{
Felix Schilk iD
}

Eingegangen: 15. Januar 2021 / Überarbeitet: 14. September 2021 / Angenommen: 21. September 2021 /

Online publiziert: 18. Oktober 2021

(C) Der/die Autor(en) 2021

Zusammenfassung In der Rechtsextremismusforschung wird die Instrumentalisierung von Religionen zu Zwecken politischer Agitation ausführlich untersucht. Der Beitrag differenziert diese Perspektive, indem er nach der Form und Funktion religiöser Deutungsmuster in rechten Krisennarrativen fragt.

In einem theoretischen Teil werden in einer wissenssoziologischen Perspektive zunächst strukturelle Gemeinsamkeiten von Konservatismus, Rechtspopulismus und der Neuen Rechten sowie Ähnlichkeiten von rechten Krisennarrativen und apokalyptischen Texten hervorgehoben. In zwei empirischen Analyseschritten werden dann (I) anhand von Quellen aus dem Umfeld der Neuen Rechten zwei metadiskursive Bezüge auf Religionskonzepte systematisiert und (II) durch die exemplarische Analyse populärer rechter Narrative die Struktur und Funktion von apokalyptischen Deutungsmustern skizziert.

Esoterische Religionsbezüge rekurrieren auf die traditionalistische Philosophie und betonen den immanenten Gehalt einer philosophia perennis. Im Rahmen exoterischer Religionsbezüge werden vor allem die sozialintegrativen Aspekte der Religion als Institution hervorgehoben. In metapolitischen Krisennarrativen werden beide Bezüge in Form von apokalyptischen Deutungsmustern aufbereitet, wobei der Figur des Katechon eine wichtige Rolle zukommt. Dabei wird deutlich, dass die Neue Rechte apokalyptische Deutungsmuster tradiert, weil sie zur Legitimation und Durchsetzung ihrer politischen Hegemonieambitionen auf permanente Krisennarrationen angewiesen ist.

Die wissenssoziologische Perspektive macht eine ambivalente Struktur neurechter Texte sichtbar und kann Anschluss- und Transformationsmöglichkeiten von rechten Narrativen und Diskursen erklären. Der Beitrag basiert auf einer diskursanalytischen Untersuchung neurechter Publikationen.

Felix Schilk (凷

Institut für Soziologie, Technische Universität Dresden, Dresden, Deutschland

E-Mail: felix.schilk@tu-dresden.de 
Schlüsselwörter Religion · Konservatismus $\cdot$ Rechtspopulismus $\cdot$ Neue Rechte Apokalyptik · Metadiskursivität

\section{"Heroism as a path to transcendence." The New Right's metadiscursive religious references and its apocalyptic discourse practice}

Abstract In research on right-wing extremism, the exploitation of religions for the purposes of political agitation has been extensively studied. This paper diversifies this perspective by asking about the form and function of religious patterns of interpretation in right-wing crisis narratives.

In a theoretical section, structural commonalities of phenomena such as conservatism, right-wing populism and the New Right as well as similarities of right-wing crisis narratives and apocalyptic texts are highlighted in a sociology of knowledge approach. In two subsequent empirical steps of analysis, (I) two references to concepts of religion are systematised on the basis of meta-discursive fragments from New Right publications, and (II) the structure and function of apocalyptic patterns of interpretation are outlined through an exemplary analysis of two popular rightwing narratives.

Esoteric religious references refer to traditionalist philosophy and emphasise the transcendent content of a philosophia perennis. Within the framework of exoteric religious references, aspects of religion as an institution in terms of social cohesion are emphasised. In metapolitical crisis narratives however, both references could be processed in the form of apocalyptic patterns of interpretation, in which the figure of the katechon plays an important role. Thereby it becomes clear that the New Right transmits apocalyptic patterns of interpretation as it relies on narratives of permanent crisis in order to legitimise and enforce its political hegemony ambitions.

The sociology of knowledge approach reveals the ambivalent structure of New Right texts and helps to understand the dispersion and transformation of right-wing narratives and discourses. The contribution is based on a discourse analysis of New Right publications.

Keywords Religion · Conservatism - Right-wing populism · New Right · Apocalypticism $\cdot$ Metadiscursivity

\section{Einleitung}

Das Verhältnis von Religion und Rechtsextremismus ist ähnlich vielschichtig wie der Rechtsextremismusbegriff, der jedoch aufgrund seiner theoretischen Unschärfe und der Entstehung im Umfeld von Sicherheitsbehörden mit ihren entsprechenden Handlungsanforderungen umstritten ist (vgl. Ackermann et al. 2015; Berendsen et al. 2019). Während der Rechtsextremismusbegriff als analytische Perspektive primär die Handlungs- und Einstellungsebene von Individuen in den Blick nimmt, zielt das Erkenntnisinteresse dieses Beitrags auf die Religionsbezüge im rechten Denken, die sich in Deutungsmustern, Weltbildern und Narrativen manifestieren. Als rechts gilt dabei ein Denken, dessen Gesellschaftsanalyse ein skeptisches Menschenbild 
zugrunde liegt und das von einem Primat der Ungleichheit ausgeht (vgl. Bobbio 1994). Diese Form des Denkens ist konstitutiv für Phänomene wie den Konservatismus, den Rechtspopulismus oder die Neue Rechte.

Wer die Frage nach religiösen Deutungsmustern im rechten Denken stellt, denkt womöglich an das Konzept der politischen Religionen, das im 20. Jahrhundert zur kritischen Analyse totalitärer Herrschaftsformen entwickelt wurde (vgl. Voegelin 1993; Vondung 1971; Faber 1997). Auch rechte Referenzautoren haben Bezüge zwischen Politik und Religion immer wieder hervorgehoben. Inspiriert von Donoso Cortés' (1933, S. 3) Behauptung, ,daß wir im Hintergrunde unserer politischen Fragen letzten Endes stets auf die Theologie stoßen“, hat etwa Carl Schmitt (1934) seine Politische Theologie formuliert. Sein Denken steht exemplarisch für eine dezisionistische Variante des Konservatismus, die im Umfeld der Neuen Rechten ausgiebig rezipiert wird. Das Verhältnis dieser Form des rechten Denkens zur Religion steht im Zentrum dieses Beitrags.

Im folgenden Kapitel stelle ich zunächst Konzeptualisierungen der Religionssoziologie vor und skizziere diverse Untersuchungsperspektiven auf das Verhältnis zwischen Religion und der extremen Rechten (Kapitel 2). Im Anschluss daran bestimme ich das Verhältnis von Konservatismus, Rechtspopulismus und Neuer Rechter und konturiere die wissenssoziologische Perspektive des Beitrags (3.1). Daran anknüpfend führe ich Ansätze der Apokalyptikforschung ein und zeige formale und funktionale Ähnlichkeiten von apokalyptischen und konservativen Narrativen (3.2).

Im empirischen Teil des Beitrags unterziehe ich dann Quellen aus dem Umfeld der Neuen Rechten einer problematisierenden Lektüre, um sie analytisch zu kategorisieren. Anhand von metadiskursiven Texten, die sich an die neurechte Community wenden, arbeite ich zwei unterschiedliche Bezüge auf Religion heraus und verorte ihre Prämissen in der Ideengeschichte (4.1). In einem weiteren Analyseschritt skizziere ich schließlich die neurechte Diskurspraxis an zwei metapolitischen Narrativen - der Erzählung des „Großen Austauschs“ und der Verschwörungserzählung „QAnon“ - und zeige exemplarisch, wie beide Bezüge für ein breiteres Publikum in der narrativen Form der Apokalyptik aufbereitet werden (4.2). Der Beitrag zeigt die besondere Anschlussfähigkeit apokalyptischer Narrative für politische Instrumentalisierungen durch rechte Akteur:innen, da sowohl ihre Struktur als auch ihre Funktion mit den Prämissen des rechten Denkens konvergieren.

\section{Religion und die extreme Rechte}

In der Religionssoziologie werden verschiedene Verständnisse von und Perspektiven auf Religion unterschieden. Pollack (2018) teilt diese Zugänge in gegenstandsspezifische, kontextuelle und dekonstruktivistische Religionsdefinitionen ein. Im Zentrum der gegenstandsspezifischen Zugänge stehe die Frage nach dem „Wesen“ der Religion und die Kategorie des „Heiligen“, während kontextuelle Zugänge nach der sozialen Funktion von Religion und ihren Bezugsproblemen fragten und die Kategorie der „Institution“ ins Zentrum stellten. Dekonstruktivistische Zugänge fragten dagegen nach der Funktion des Religionsbegriffs in politischen Diskursen. 
Untersuchungen zum Verhältnis von Religion und der extremen Rechten liegen ebenfalls unterschiedliche Zugänge zugrunde. Felix Wiedemann (2016) hat in einem Überblicksbeitrag drei Untersuchungsperspektiven skizziert. Der religiöse Charakter der extremen Rechten zeige sich in der völkischen Ideologie sowohl in der Mystifizierung zentraler Kategorien wie „Volk“ und „Rasse“ als auch in heilsgeschichtlichen Narrativen. Auch rituelle Vergemeinschaftungsformen und institutionalisierte Verhaltensweisen wie Helden- und Märtyrerkulte hätten einen religiösen Charakter (vgl. ebd., S. 513-519). Das Verhältnis der extremen Rechten zu den monotheistischen Religionen sei dagegen uneindeutig. Neben einem strikten Antimonotheismus, der vor allem die neopaganistische Neue Rechte auszeichne, gebe es positive Bezüge auf das „christliche Abendland“ (vgl. ebd., S. 519-522). Anhand von Texten aus der neurechten Zeitschrift Sezession hat Samuel Salzborn (2015, S. 290ff.) unterschiedliche politische Instrumentalisierungen der Weltreligionen im Denken der Neuen Rechten herausgearbeitet. So fungiere das Christentum als „,das Eigene“, der Islam als ,das Fremde“ und das Judentum als „das Andere“. Das Verhältnis von Religionen zur extremen Rechten ist ebenfalls ambivalent. Wiedemann (2016, S. 522-526) weist auf den Antimodernismus hin, der sowohl für fundamentalistische religiöse Strömungen als auch für die extreme Rechte konstitutiv sei. Auch die antiuniversalistische und antinormative Ausrichtung vieler esoterischer Denkmodelle sei strukturell anschlussfähig an rechte Denkformen. Ein Konfliktfeld zwischen religiösen und politischen Akteur:innen liege dagegen in der Frage, ob der Religion oder dem Politischen der Primat zukomme.

In der empirischen Forschung sind bisher vor allem Zusammenhänge von religiösen und rechten Einstellungen sowie die politische Instrumentalisierung von Religion durch rechtspopulistische Parteien untersucht worden, etwa die Mobilisierung von laizistischen Werten gegen den Islam (vgl. Bizeul 2018), die Polarisierung von Christen bezüglich rechtspopulistischer Inhalte (vgl. Pickel 2018) oder die Rolle von religiösen Interessengruppen innerhalb rechter Parteien (vgl. Althoff 2018; Botsch 2020). Grundlage für die Einstellungsforschung ist die bekannte Studie von Gordon W. Allport (1966, S. 455) zum Zusammenhang von Vorurteilen und Religion, in der er zwischen einer extrinsischen und intrinsischen Form der Religiosität unterscheidet. Extrinsische Religiosität liege vor, wenn die religiösen Praktiken nicht aus Identifikation mit den Glaubensinhalten, sondern vor allem aufgrund von Konventionalität und der Aussicht auf persönliche Vorteile durch eine Art ,religious tokenism" (ebd., S. 454) befolgt werden. Für die intrinsische Form sei dagegen die selbstlose Suche nach religiöser Transzendenz leitend. Durch Befragungen mit Vorurteilsskalen kam Allport zu dem Befund, dass eine extrinsische Religiosität mit einem erhöhten Vorurteilswert einhergehe, während eine intrinsische Religiosität der Zustimmung zu Vorurteilen entgegenwirke. In der Rechtsextremismusforschung wurden die Ergebnisse der Studie als „Allport-Paradoxon“ rezipiert: Religiöse Einstellungen können Rechtsextremismus sowohl befördern als auch hemmen; entscheidend sei, ob es sich um einen exklusiven oder einen inklusiven Religionsanspruch handelt (vgl. Rebenstorf 2018).

An diese Befunde knüpfen implizit auch Hidalgo et al. (2019, S. 3) in einem aktuellen Argumentationspapier für die Hans-Seidel Stiftung zu „Religion und Rechtsextremismus“ an. In der Inanspruchnahme der Religion durch Rechtspopulist:innen 
sehen sie primär einen säkularen Impuls, der aus strategischen Gründen erfolge. Religion werde in rechtspopulistischer Verwendung - analog zur extrinsischen Religiosität - zu einem „Identitätsmerkmal degradiert, das ein Gefühl der Zugehörigkeit jenseits konkreter religiöser Glaubensinhalte vermittelt“ (ebd., S. 5). Hidalgo et al. schlagen deshalb vor, konservativ-christliche und rechtspopulistische Positionen analytisch voneinander abzugrenzen und durch die jeweilige Haltung gegenüber Demokratie und Religionsfreiheit zu bestimmen (vgl. auch Hidalgo 2018). Dem schließt sich die Publizistin Liane Bednarz (2020, S. 14) an, die in ihrer Auseinandersetzung mit Rechtspopulist:innen und Akteur:innen der Neuen Rechten darauf bedacht ist, die Begriffe „konservativ“ und „rechts“ voneinander zu unterscheiden, und konstatiert, dass es rechten Religionsvorstellungen einer konsistenten Theologie ermangele. Stattdessen betrieben rechte Autor:innen „Rosinenpickerei“ zur Bestätigung ihres eigenen Weltbildes (vgl. ebd., S. 10; Bednarz und Schäller 2021). Gegen Hidalgo et al. und Bednarz lässt sich jedoch kritisch einwenden, dass ihre Unterscheidung von konservativ-religiösen und rechtspopulistischen bzw. (neu-)rechten Positionen begrifflich unscharf bleibt und zum Teil normativen Erwägungen folgt. ${ }^{1}$ Bednarz verzichtet auf eine Begriffsbestimmung des komplexen und ambivalenten Konservatismus und verkürzt ihn ausschließlich auf die „liberal-konservative“ Spielart, die sich im Umfeld der deutschen Christdemokratie nach 1945 durchgesetzt habe. Das klingt, zugespitzt gesagt, so, als gebe es eine richtige intrinsische Religiosität und die falsche strategische Instrumentalisierung der Religion durch die Neue Rechte. Diese binäre Gegenüberstellung verkennt aber, dass die Sozialgeschichte der Religion von Anfang an durch Kämpfe um Deutungshoheit und die Vermischung von religiösen und politischen Interessen geprägt ist.

Wie ich im Folgenden zeige, stehen Rechtspopulist:innen und neurechte Akteur:innen durchaus in einer Traditionslinie des konservativen Denkens, bestimmt sich der Konservatismus doch weniger durch seine Haltung gegenüber der demokratischen Verfassung und den Institutionen der Bundesrepublik als durch tradierte Menschen- und Gesellschaftsbilder und den Rückgriff auf spezifische Krisennarrative. Innerhalb des rechten Denkens lassen sich sowohl Bezüge zu intrinsischer als auch zu extrinsischer Religiosität ausweisen. Beide Bezugnahmen sind in neurechten Texten häufig von einem ,apokalyptischen Ton“ (Schnickmann 2021, S. 151) durchzogen.

\section{Wissenssoziologische Grundlagen}

In meinem Beitrag nehme ich eine wissenssoziologische Perspektive ein, in der der Konservatismus ausgehend von Karl Mannheims (1984, S. 111) Konservatismusstudie als „Reflexivwerden“ eines lebensweltlichen tacit knowledge verstanden wird. Mannheim sieht im Konservatismus einen Denkstil, der sich weniger durch

\footnotetext{
${ }^{1}$ Die normative Unterscheidung eines demokratischen Konservatismus von illiberalen rechten Einstellungen ist angesichts des Sprechorts der beiden Texte (Argumentationspapiere) und ihres adressierten Publikums (politische und zivilgesellschaftliche Akteur:innen) zwar nachvollziehbar, geht aber zu Lasten einer differenzierten Analyse.
} 
ein politisches Programm als durch argumentative Figuren, spezifische Deutungsmuster sowie bestimmbare soziale Trägergruppen auszeichnet. Historisch entstand das konservative Denken aus der Opposition ständischer Kräfte gegen die bürgerliche Gesellschaft und den Liberalismus der Aufklärung. Mannheims These ist, dass die Trägergruppen der ständischen Lebenswelt erst durch die Konkurrenzerfahrung mit dem aufsteigenden Bürgertum ein Selbstbewusstsein ihrer sozialen Position erlangten. In diesem Prozess transformierte sich ihr implizites Alltagswissen in ein politisches Bewusstsein. Diese Perspektivverschiebung und der Blick auf soziale Latenzen, der dem Konservatismus eigen ist, hat viele Ähnlichkeiten zum Grundimpuls der modernen Soziologie. In der Fachgeschichtsschreibung ist daher vielfach auf diesen konservativen Ursprung der Soziologie hingewiesen worden (vgl. Nisbet 1952; Maus 1956; Macherey 1992; Spaemann 1998; Reitz 2016).

\subsection{Konservatismus}

Die historische Entstehung des Konservatismus lässt sich durch den Verweis auf eine wissenssoziologische Methode, das ethnomethodologische Krisenexperiment Harold Garfinkels (1967), nachvollziehen. Durch die Entstehung der bürgerlichen Gesellschaft der Neuzeit und die dadurch ausgelösten Veränderungen erodierten die Regelstrukturen, Sinnhorizonte und Valorisierungsregime der feudalen Lebenswelt, die dadurch sichtbar wurden. Der Konservatismus als politische Ideologie ist der Versuch, diesen Verlust an lebensweltlichen Orientierungen sinnhaft zu deuten und in eine politische Bearbeitung zu überführen (vgl. Mannheim 1984).

Martin Greiffenhagen (1986, S. 122) versteht das konservative Denken daher als „Ausdruck eines Zeitwendebewußtseins“, dem eine Hermeneutik einer sozialen Krise zugrunde liege (vgl. ebd., S. 347); Kurt Lenk (1989, S. 50) spricht analog von einer „Form der Enttäuschungsverarbeitung“, deren politische Aspekte nur schwer von ihren weltanschaulichen Grundlagen zu trennen seien. Das, woraus sich der Konservatismus speise, sei „kein primär politischer Impuls, sondern eine Weltsicht, eine spezifische Form des Wirklichkeitsverständnisses, ein Deutungsmuster.“ Im Anschluss an Michael Makropoulos (1997) und Niklas Luhmann (1974) lässt sich der Konservatismus als eine Verarbeitung des modernen Kontingenzbewusstseins verstehen.

Dieses wissenssoziologische Verständnis des Konservatismus unterscheidet sich von verbreiteten politikwissenschaftlichen (vgl. Hacke 2006; Steber 2017) oder feuilletonistischen (vgl. Kühnlein 2019) Ansätzen, die nach stabilen konservativen Grundüberzeugungen sowie institutionellen und parteiförmigen Ausprägungen des Konservatismus suchen, dadurch, dass es das konservative Denken von der lebensweltlichen Position seiner Trägergruppen her analysiert. Statt einer behaupteten Objektkonstanz des Konservatismus steht dabei die soziale Konstellation, in der sich das Objekt befindet, im Fokus. Mit dieser Perspektive können der dynamische Wandel des Konservatismus und seine mannigfaltigen historischen Spielarten (vgl. Vierhaus 1982; von Beyme 2013) besser erklärt werden. Der soziale Ort des Konservatismus ist dort, wo einst hegemoniale Lebenswelten vom Verlust ihrer Privilegien bedroht sind und in die „Peripherie“ (Mannheim 1984, S. 84) gedrängt werden. 
Die sozialen Trägergruppen des konservativen Denkens können sich daher durch historische Transformationsprozesse verändern. ${ }^{2}$

Dennoch lassen sich weltanschauliche und gesellschaftstheoretische Kontinuitäten des Konservatismus bestimmen, die sich aus der historisch tradierten Oppositionshaltung seiner Trägergruppen gegen den Aufklärungsliberalismus und die moderne, funktional differenzierte Gesellschaft ergeben. Dazu gehören der Glaube an eine fundamentale Ungleichheit und die Insuffizienz des Menschen (Mängelwesen), die daraus abgeleitete Notwendigkeit von sozialen Hierarchien, Skepsis gegenüber Utopien sowie die transzendente Legitimation von Herrschaft durch eine ontologische Vorstellung von Ordnung, die nicht vollständig intelligibel sei und der daher mit einer Haltung der Unterwerfung und Anerkennung begegnet wird (vgl. Lenk 1989, S. 30ff.; Greiffenhagen 1986, S. 83ff.).

\subsection{Rechtspopulismus und Neue Rechte}

Im Rechtspopulismus und in der Neuen Rechten werden diese Motive in Form von Ontologien und Deutungsmustern rezipiert und tradiert. Beide zeichnen sich allerdings durch einen weltanschaulichen Eklektizismus aus, der theoretische Begründungen primär für praktische Ziele sucht (vgl. Elm 1986, S. 134). Beide Tendenzen, die instrumentelle Grundhaltung und die weltanschaulichen Ontologien, zeigen sich in unterschiedlichen Religionsbezügen im rechten Denken, die ich im anschließenden Kapitel herausarbeite.

Der Rechtspopulismus hat ebenso wie der Konservatismus einen ambivalenten Charakter, der sich in der Konkurrenz von unterschiedlichen Definitionen widerspiegelt. Er wird u.a. als ,politischer Stil“ (vgl. Moffitt 2016), als „dünne Ideologie“ (vgl. Mudde 2004), als antipluralistische Politikvorstellung (vgl. Müller 2016) oder als Hegemoniestrategie (vgl. Mouffe 2018) konzeptualisiert - je nachdem, ob die strategische, ideologische oder formale Komponente stärker gewichtet wird. Wird jedoch ein soziologischer Populismusbegriff zugrunde gelegt, der den Populismus als politische Reaktion auf Modernisierungsschübe und sektorale Anpassungskrisen (vgl. Priester 2007, S. 28f.) versteht, die sich ,,aus der Erinnerung an eine noch wenig differenzierte Gesellschaft“ (Dubiel 1986, S. 36) speise und durch „Statusängste oder kollektive Kränkungen“ (ebd., S. 44) verstärkt werde, werden Strukturähnlichkeiten von Rechtspopulismus und Konservatismus deutlich. Rechtspopulismus lässt sich dann als eine Hegemoniestrategie verstehen, die lebensweltliche Verlusterfahrungen adressiert und politisch kapitalisiert. Dieser Doppelcharakter von zeitdiagnostischer Analytik und politischen Hegemonieambitionen ist nicht nur typisch für den Konservatismus und Rechtspopulismus, sondern auch für die Neue Rechte.

\footnotetext{
${ }^{2}$ Im historischen Verlauf können das unterschiedliche Gruppen sein, wie der Adel im nachrevolutionären Frankreich, die Plantagenbesitzer der US-amerikanischen Südstaaten nach Abschaffung der Sklaverei als ökonomischer Basis der Baumwollproduktion, die Frontgeneration des Ersten Weltkrieges und die enteigneten ostelbischen Junker in der Weimarer Republik, Bauern und Kleingrundbesitzer während der Kollektivierung der Landwirtschaft in der Sowjetunion, das poujadistische Kleinbürgertum in der französischen Konsumgesellschaft, das an seinen Distinktionspraktiken festhaltende Bürgertum in der DDR oder die vom fordistischen Klassenkompromiss der Trentes Glorieuses profitierende Industriearbeiterschaft im postindustriellen Transformationsprozess.
} 
Die metapolitische Neue Rechte muss vom (partei-)politischen Rechtspopulismus unterschieden werden, auch wenn beide Phänomene zahlreiche Schnittmengen aufweisen. Als Neue Rechte wird ein bewegungspolitisches Milieu verstanden, das sich seit den späten 1960er-Jahren primär um Zeitschriftenprojekte und Thinktanks gruppiert sowie rechte Theorie und Praxis unter den Bedingungen moderner Massendemokratien und ihrer ausdifferenzierten Öffentlichkeiten modernisiert (vgl. Greß et al. 1990). Im Zentrum stand dabei ein von Antonio Gramsci gekapertes kulturrevolutionäres Verständnis von politischer Hegemonie. Von der parteipolitischen Rechten unterscheidet sich die Neue Rechte durch ihren Fokus auf die vorpolitische Sphäre der Kultur. Durch eine „Metapolitik“ genannte Diskurspraxis sollen langfristig rechte Milieus und Mentalitäten geprägt, Begriffe und Deutungsmuster im öffentlichen Diskurs verankert und zentrale Schnittstellen von Politik, Medien, Bildung, Wissenschaft und Zivilgesellschaft besetzt werden (vgl. Weiß 2017, S. 54ff.). Die Neue Rechte tritt dabei als strategischer Akteur auf, der disparate rechte Strömungen in Diskursallianzen zusammenbringt. Wolfgang Gessenharter (1994, S. 124) spricht von der „Scharnierfunktion der Neuen Rechten zwischen Rechtsextremismus und Konservatismus“.

In neurechten Publikationen werden unterschiedliche Publika adressiert. Neurechte Texte haben deshalb sowohl analytische als auch narrative Anteile. Sie sind sowohl Teil von Diskursen, machen diese Diskurse aber auch zum Gegenstand von „metadiskursiven“ Reflexionen (vgl. Meier-Vieracker 2020). Die narrative Dimension dieser Texte kann mit Heuristiken der Apokalyptikforschung erschlossen werden.

\subsection{Apokalyptik}

Im Alltagsverständnis wird die Apokalypse häufig mit Katastrophen- und Untergangsszenarien gleichgesetzt. In der Apokalyptikforschung versteht man darunter jedoch eine literarische Gattung, die aus der Analyse von religiösen Texten entwickelt wurde und als ,traditions- und folgenreiche Auslegung von Kontingenz und Krise“ (Weymann 2008, S. 14) auch in anderen Texten nachgewiesen werden kann. ${ }^{3}$ Von Interesse ist dabei nicht nur der Text, sondern darüber hinaus der nichttextuelle Kontext wie die Intentionen und Dispositionen der Autor:innen (vgl. Brokoff 2001, S. 8f.).

Im Anschluss an Karl Mannheims Studien zum utopischen Bewusstsein hat der Literaturwissenschaftler Klaus Vondung (1988, S. 46ff.) die Apokalypse einerseits als „Text“, andererseits als „Symbolik der Erfahrungsauslegung“ bestimmt, deren inhaltliche Definition schwierig sei. Stattdessen fragt Vondung (1988, S. 48) nach den Erfahrungen, die ,die Produktion apokalyptischer Texte angestoßen haben“. Laut Bernd U. Schipper (2008, S. 87f., 95, 82) entstanden derartige Texte im antiken Judentum und der hellenistischen Zeit vor dem Hintergrund politischer Veränderungen und wurden von marginalisierten ehemaligen Eliten formuliert, die dadurch die Zentralgewalt neu legitimieren wollten. Wie der Konservatismus artikuliert sich auch die Apokalyptik aus der Warte einer spezifischen Beobachtungsposition als

\footnotetext{
${ }^{3}$ Das bekannteste Beispiel ist die „Offenbarung des Johannes“ im Neuen Testament, allerdings lassen sich apokalyptische Traditionen bis ins 3. Jahrtausend v.u.Z. zurückverfolgen (vgl. Schipper 2008, S. 78ff.).
} 
Deutungsmuster des „Übergangs vom Alten zum Neuen“ (Brokoff 2001, S. 15) und als Erzählung des „,vollständigen Untergangs der bisherigen Welt“ (ebd.).

In der jüngeren Apokalyptikforschung (vgl. Nagel et al. 2008) wurde dieser Fokus erweitert, indem nach der Funktion apokalyptischer Rhetoriken gefragt wird. Man dürfe die Apokalypse nicht nur als Deutungsmuster verstehen, sondern müsse sie auch als „Diskursmacht“ (ebd., S. 308) ernstnehmen. So stehe die apokalyptische Rede im ,pragmatischen Spannungsfeld zwischen Ideen und Interessen“ (Nagel 2008a, S. 134) mit „Folgen für die Interessenausrichtung des praktischen Handelns“ (Weymann 2008, S. 15). Jürgen Brokoff (2001, S. 24) zufolge liegen die Gründe für diese „Doppelstruktur“ in der apokalyptischen Sprechsituation. Einerseits beanspruchen apokalyptische Texte die Erkenntnis einer transzendenten Wahrheit, andererseits ermächtigen sie sich selbst durch den verkündeten Wahrheitsanspruch: „Das stärkste Motiv des apokalyptischen Textes besteht deshalb darin, von der Transzendenz aus zu sprechen und im Namen dieser Transzendenz die anderen, die nichttranszendenten Texte mit dem Hinweis auf deren Weltlichkeit zu vernichten. Das Ziel des apokalyptischen Textes ist die Installierung eines diskursiven Regimes, in dem allein er selbst noch zu sprechen vermag." (Ebd., S. 28).

Wenn die Moderne durch ein spezifisches Kontingenzbewusstsein charakterisiert wird (vgl. Makropoulos 1997), dann sind Apokalyptik und Konservatismus ambivalente Phänomen. Ihre Gegenentwürfe sind antimodernistisch und verschließen die Möglichkeit von Kontingenz durch Transzendenzbehauptungen. Zugleich übernehmen sie Strukturmerkmale der Moderne in ihre Narrationen und Anrufungen (vgl. Nagel 2008b, S. 57). Wie ich im Folgenden zeige, besteht zwischen apokalyptischen Deutungsmustern und konservativen Krisennarrativen nicht nur eine Strukturähnlichkeit, beide konvergieren auch in ihrer jeweiligen Funktion als diskursives Regime. Für Rechtspopulist:innen und Neue Rechte sind apokalyptische Erzählungen aufgrund ihrer Doppelstruktur und ihres Appellcharakters attraktiv.

\subsubsection{Apokalyptische Narrative}

Konstitutiv für klassische apokalyptische Texte ist die dualistische Unterscheidung von Transzendenz und Immanenz, die mit einem narrativen Dreischritt verknüpft ist (vgl. Schipper 2008, S. 78). Die immanente Welt der Gegenwart geht dem Ende entgegen, wird durch den Weltuntergang vernichtet und im Anschluss daran als transzendente Welt neu errichtet. Diese dualistische Unterscheidung wird durch ,,semantische Oppositionen“ wie Unreinheit - Reinheit, Gut - Böse oder Wahrheit Lüge verstärkt (vgl. Brokoff 1999, S. 15ff.). Die Hoffnung auf einen transzendenten Neuanfang verleiht der klassischen Apokalypse einen eschatologischen Charakter. Die apokalyptische Struktur ist daher nicht genuin konservativ, sondern ebenso in politischen Utopien der Neuzeit zu finden.

Klaus Vondung (1988, S. 106) konstatiert für die Neuzeit jedoch einen Wandel der narrativen Struktur, den er ,kupierte Apokalypse“ nennt. Die kupierte Form der Apokalypse ist um die Idee des utopischen Neuanfangs beschnitten und ,,beschränkt sich auf die Vision des Untergangs“. Claudia Gerhards (1999, S. 37) hat diesen Befund als ,inverse Apokalypse“ bezeichnet, in der der narrative Dreischreit umgekehrt werde: Eine funktionierende Welt bricht zusammen und versinkt im Chaos. 
Konservative Krisennarrative bewegen sich in der Formentradition dieser kupierten oder inversen Apokalypsen.

Zentral für diese konservative Form ist die Figur des „Katechon“ (griech. Aufhalter) aus dem zweiten Brief des Paulus an die Thessalonicher, mit der er auf die Parusieverzögerung reagierte (vgl. Nagel 2008a, S. 143f.). Demzufolge könnten das Jüngste Gericht und die Wiederkehr Christi nicht eintreten, bevor nicht der Feind Gottes in Form des Antichristen erschienen sei. Dieser werde jedoch durch das oder den Katechon aufgehalten. Das oder der Katechon ist somit eine ambivalente Figur, die einerseits die Welt vor dem Antichristen bewahrt und andererseits die christliche Erlösung verzögert. In der katholischen Theologie spielt die Figur keine zentrale Rolle, allerdings ist sie Ausdruck einer umfangreichen ,Rezeptionsgeschichte bewahrender apokalyptischer Rhetorik“ (ebd, S. 135) und bietet Anknüpfungspunkte für eine weltliche Politisierung (vgl. ebd, S. 144). Laut Alexander-Kenneth Nagel (2008a, S. 156) ,liegt mit der katechontischen Geschichtstheologie ein konservativer Diskursstrang vor, der sich zur klassischen Apokalypse komplementär bzw. parasitär verhält".

Der Dualismus von Immanenz und Transzendenz findet sich nicht nur in apokalyptischen Texten, sondern ist auch konstitutiv für das Kontingenzbewusstsein des konservativen Denkens und das „Reflexivwerden“ (Mannheim 1984, S. 111) des lebensweltlichen tacit knowledge. Unabhängig voneinander haben der Religionssoziologe Nagel und der Politikwissenschaftler Martin Greiffenhagen diese Ähnlichkeit registriert: ,der katechontische Aufruf zu ambitionierter Erhaltung bzw. zu proaktiver Restauration begleitet globale Krisenzeiten mit seismographischer Sicherheit.“ (Nagel 2008a, S. 151) „Der moderne europäische Konservatismus begleitet das Zeitalter der Revolutionen als Krisenphänomen. [...] Die Sozialwissenschaften sind als Krisenwissenschaften Produkt jenes gesellschaftlichen Umbruchs, den der Konservatismus seismographisch notiert.“(Greiffenhagen 1986, S. 347ff.).

\subsubsection{Rechte Krisennarrative}

Die narrative Spannung apokalyptischer Texte findet sich in rechten Krisendiagnosen in Form von Dekadenzerzählungen (vgl. Lenk 2005, S. 50), die dem Dreischritt „Dekadenz - Apokalypse - Heroismus“ folgen und der katechontischen Form der inversen Apokalypse entsprechen. Ausgangspunkt der Dekadenzdiagnosen ist die kulturkritische Figur der Entzweiung bzw. Entfremdung, die in rechten Narrativen auf zwei unterschiedliche Weisen rezipiert wird.

Eine Rezeptionslinie geht auf den Traditionalismus und die philosophia perennis zurück. Diese Idee einer transzendenten, ,ewigen Philosophie“ hatte der italienische Priester Marsilio Ficinos im 15. Jahrhundert formuliert. Demzufolge liege der Ursprung aller Religionen in einer einzigen Ur-Religion, die sich anschließend ausdifferenziert habe (vgl. Sedgwick 2019, S. 46). Der Traditionalismus erweiterte diese Vorstellung durch das Konzept der Inversion, das die Menschheitsgeschichte als fortschreitende Entfremdung von dieser Ur-Religion deutet. Die traditionalistische Philosophie wurde durch Autoren wie René Guénon und Julius Evola popularisiert und hat starke Parallelen zu Martin Heideggers Fundamentalontologie. Heute 
wird sie prominent durch den russischen Neurechten Alexandr Dugin vertreten (vgl. Boutin 2017, S. 345f.; Umland 2019).

Der moderne Konservatismus mit seinem immanenten Primat der philosophischen Anthropologie hat dagegen ein tendenziell affirmatives Verhältnis zur Entfremdung (vgl. Gehlen 1963). Das skeptische Menschenbild der philosophischen Anthropologie setzt voraus, dass der Mensch als Mängelwesen gedacht wird und kultureller Artefakte bedarf, die den Sinnüberschuss seiner Handlungen reduzieren. Diese Artefakte beziehen ihre primäre Legitimation aus ihrer bloßen historischen Existenz. Rechtfertigen muss sich in den Augen des modernen Konservatismus, wer den Latenzschutz historisch gewachsener Strukturen in Frage stellt. An die Stelle der transzendenten Erlösungshoffnung, die im traditionalistischen Denken noch enthalten ist, tritt im modernen Konservatismus der fatalistische amor fati, die Unterordnung unter immanente Institutionen. Die Figur der Entzweiung wird dafür ins Politische verschoben und als Kritik der funktionalen Differenzierung entfaltet, der zugeschrieben wird, die Autorität der Institutionen zu untergraben. Konservative Krisendiagnosen der Neuzeit konstatieren daher als gefährliche Folge der bürgerlichen Revolution eine problematische Trennung von Staat und Gesellschaft, bei der die Autorität des souveränen Staates durch miteinander konkurrierende Interessengruppen zersetzt werde (vgl. Koselleck 1973) - auch das ist eine Erzählstruktur in der Form der inversen Apokalypse.

Der Beginn der Neuzeit und die funktionale Differenzierung der Gesellschaft, durch die sich auch die Form der politischen Herrschaft verändert, wird in konservativen Narrativen als Interregnum betrachtet - als eine von Anarchie und Bürgerkrieg geprägte Übergangszeit, die durch die Wiedererrichtung einer politischen Zentralgewalt beendet werden müsse. Diese Denkfigur ist auch konstitutiv für die rechte Reichsidee und den konservativen Abendlanddiskurs (vgl. Weiß 2017, S. 164ff.; Korsch 2020). Ihre Funktion besteht darin, ein hegemoniales politisches System und seine Eliten zu diskreditieren, ihre Legitimität in Frage zu stellen und die eigenen Ordnungsvorstellungen als Alternative zu empfehlen. Wenn die Statuspositionen konservativer Trägergruppen durch beschleunigte Transformationsprozesse von einem Bedeutungsverlust bedroht sind, haben derartige Narrative besondere Konjunktur. In Deutschland betrifft das vor allem die Transformationszeiten nach der Niederlage des Kaiserreiches im Ersten Weltkrieg und der Liberalisierung der westdeutschen Konsumgesellschaft in den 1960er-Jahren. In beiden Zeiträumen vollzog sich eine Modernisierung des konservativen Denkens dadurch, dass Ordnungsambitionen durch eine voluntaristische Handlungsphilosophie ergänzt wurden. Die Ambivalenz des Katechon, zugleich antiutopisch und heroisch-aktivistisch zu sein, ist exemplarisch für die Idee einer solchen „Konservativen Revolution“.

In der Apokalyptikforschung sind rechte Schriften der Zwischenkriegszeit bereits exemplarisch auf apokalyptische Motive untersucht worden (vgl. Vondung 1988, S. 383ff.; Brokoff 2001). Von Autoren aus dem Umfeld der „Konservativen Revolution“ (vgl. Greiffenhagen 1986, S. 241ff.; kritisch Weiß 2017, S. 39ff.) wie Ernst Jünger, Hans Freyer und Carl Schmitt wurde die katechontische Deutung intensiv rezipiert. Auch die Neue Rechte zählt die Figur des Katechon zu ihren Leitbegriffen (vgl. Weißmann 2009a). Der neurechte Publizist Gerd-Klaus Kaltenbrunner (1977) hat Jüngers „heroischen Realismus“ einmal als „Konservative Apokalypse“ 
bezeichnet. Wie ich nun am Material zeigen werde, beziehen sich metadiskursive Texte der zeitgenössischen Neuen Rechten sowohl auf transzendente als auch auf immanente Argumentationsmuster. Die an diese Bezüge anschließenden neurechten Krisennarrative sind von apokalyptischen Motiven durchzogen.

\section{Religiöse Deutungsmuster in neurechten Texten}

Der folgenden Analyse liegt unterschiedliches Quellenmaterial zugrunde. In einem ersten Schritt werden aus metadiskursiven Texten der Neuen Rechten unterschiedliche Bezüge auf Religion herausgearbeitet und systematisiert. Die ausgewählten Textfragmente stammen aus dem französischsprachigen ,dictionnaire du conservatisme“, zu dem Autor:innen aus dem Umfeld der französischen Nouvelle Droite Artikel beigesteuert haben, und zentralen Publikationen des einflussreichen neurechten Thinktanks „Institut für Staatspolitik“ - dem „Staatspolitischen Handbuch“ und der institutseigenen Zeitschrift „Sezession“ (vgl. Pfahl-Traughber 2017) -, die im Anschluss an die Grounded Theory codiert und kontrastiert wurden (vgl. Keller 2008). Gegenüber dem Material wurde eine doppelte Analysehaltung eingenommen. Die metadiskursiven Texte dienen sowohl als Informationsquelle zur Theoriegenese als auch als Material für die Bildung von analytischen Kategorien und eröffnen eine Binnenperspektive auf das Denken der Neuen Rechten.

In einem zweiten Analyseschritt wird die Diskurspraxis der Neuen Rechten in den Fokus genommen, indem neurechte Narrative, die an ein breiteres Publikum kommuniziert werden, untersucht werden. Anhand exemplarischer Textausschnitte aus dem Umfeld der „Identitären Bewegung“ skizziere ich mit Heuristiken der Apokalyptikforschung die Struktur der Erzählung vom „Großen Austausch“ und der Verschwörungstheorie „QAnon“. ${ }^{4}$ Beide Narrative unterscheiden sich inhaltlich, haben auf der Ebene der Textstruktur jedoch viele Gemeinsamkeiten, die aus einer geteilten Funktion - der Diskursmacht der Apokalypse - resultieren.

\subsection{Metadiskursive Religionsbezüge}

Obwohl er keinen direkten Bezug zum „Allport-Paradoxon“ herstellt, zeigt Hans Richard Reuter (2018) in einem Beitrag über „Nation und Religion im Denken der deutschen Neuen Rechten“, wie sich die der Einstellungsforschung zugrundeliegende Heuristik von intrinsischer und extrinsischer Religiosität auf die Ebene von Diskursen übersetzen lässt. Reuter schließt an die verbreitete Unterscheidung zwischen einem substantiellen und einem funktionalen Religionsbegriff an und konstatiert, dass sich die deutsche Neue Rechte im Umfeld der Zeitschrift Sezession ,dezidiert gegen einen funktionalen Religionsbegriff“ (ebd., S. 22) wende. Stattdessen dominiere die Vorstellung ,einer vom Heiligen durchwirkten integralen Wirklichkeit, die sich rationaler Erfassung entzieht und durch mythische Ursprungserzählungen vergegenwärtigt wird“ (ebd., S. 23). Laut Reuter (2018, S. 21) bietet sich im neurechten

\footnotetext{
${ }^{4}$ Eine ausführliche Analyse zugehöriger Texte ist im Rahmen dieses Artikels nicht möglich. Nagel (2021) zeigt in kleineren Fallstudien weitere apokalyptische Aspekte beider Narrative.
} 
Denken deshalb kaum eine Anknüpfung an das Christentum an; naheliegender seien Rekurse auf pagane und neuheidnische Religionskonzepte, wie sie auch in der französischen Nouvelle Droite vertreten werden. Damit vereindeutigt Reuter jedoch die ambivalenten Religionsbezüge im rechten Denken und übersieht, dass der Paganismus zwar in der Anfangszeit der französischen Nouvelle Droite dominant gewesen ist, mittlerweile aber auch durch affirmative Bezüge auf einen konservativen Katholizismus und die orthodoxe Kirche ergänzt wird (vgl. Chemin 2017). Wie ich zeigen werde, stehen im rechten Denken sowohl substantielle als auch funktionale Bezüge auf Religion, die sich aus je unterschiedlichen theoretischen Quellen speisen, relativ spannungsfrei nebeneinander.

Beide Bezüge werden auch in metadiskursiven Quellen aus dem Umfeld der Neuen Rechten angesprochen. So wird im französischsprachigen ,dictionnaire du conservatisme“ unter dem Stichwort „Religion“ auf Henri Bergson verwiesen, der zwischen einer dynamischen und einer statischen Religion unterschieden habe (vgl. Guillaud 2017, S. 798). Die dynamische Funktion umschreibe den direkten Zugang des Individuums zur Göttlichkeit (divinité) und Spiritualität, während die statische Funktion auf Ordnung, Einheit, Stabilität und ein kognitives Fundament für die Organisation des Sozialen ziele. Aufgrund dieses Doppelcharakters der Religion bestehe eine Spannung zwischen einer sozial-konservierenden (social-conservatrice) und einer individuell-befreienden (individuelle-libératrice) Funktion. Seit der Aufklärung habe der Konservatismus jedoch eine Affinität zur statischen - d.h. funktionalen Seite der Religion. Auch im „Staatspolitischen Handbuch“ des neurechten Instituts für Staatspolitik wird Religion als eine „,konservative Kraft ersten Ranges“ (Weißmann 2009b, S. 132) bezeichnet und mit Verweis auf Cicero zwischen religio und religere unterschieden: „Was die erste Interpretation betrifft, spräche für sie die auBerordentliche Bedeutung, die dem Kult in allen bekannten R. zukommt, dessen Vorschriften eingehalten werden müssen, um den - immer potenziell gefährlichen Kontakt mit dem Göttlichen sicherzustellen, während für die zweite Alternative der Aspekt der Innerlichkeit genannt werden könnte, nämlich die sehr stark von Emotionen und irrationalen Momenten bestimmte Bindung des einzelnen an ein oder mehrere göttliche Wesen." (ebd.).

Diese doppelte Referenz auf Religion im rechten Denken führe ich im Folgenden anhand von weiteren Schlüsseltexten zum Thema „Religion“ exemplarisch aus, kontextualisiere sie in einem theoretischen und ideengeschichtlichen Kontext und weise auf Ambivalenzen der gegenwärtigen Rezeption hin. Dabei nutze ich in Anlehnung an die binären Kategorien von Allport (1966), Guillaud (2017) und Reuter (2018) die idealtypische Unterscheidung zwischen esoterischen und exoterischen Religionsbezügen.

\subsubsection{Esoterische Religionsbezüge: Die integrale Tradition}

Unter esoterischen Religionsbezügen werden Referenzen auf Religion verstanden, für die ein substantialistischer Religionsbegriff leitend ist. Diese esoterische Religiosität lässt sich vor allem an Texten aufzeigen, die sich in eine Rezeptionslinie der traditionalistischen Philosophie stellen. So hat etwa der rumänische Traditionalist Mircea Eliade (1957; vgl. Sedgwick 2019, S. 166) die Vorstellung einer philoso- 
phia perennis in ein ontologisches Modell überführt, das die Welt in zwei fundamental voneinander getrennte Sphären teilt. Sein Hauptwerk „Das Heilige und das Profane“ wird heute von der Neuen Rechten als „Schlüsselwerk“ rezipiert. Im „Staatspolitischen Handbuch“ schreibt Wolfgang Saur (2010, S. 117) über „Eliades Essentialismus, dem der menschliche Kern als unverfügbar gilt“ und der ,zahlreichen Lesern wieder eine Ahnung der religiösen Erfahrung und Welttiefe vermittelt". Der Bezug auf Eliade erfolgt aber nicht ausschließlich substantialistisch, wie Reuter (2018, S. 22) fälschlicherweise unterstellt. Saur (2010, S. 116) kontextualisiert den Mythos als Teil des Heiligen auch in einer religionssoziologischen Deutung, die er affirmativ wendet, und befragt ihn auf seine Funktion: „Das zeigen auch Sinn und Funktion des Mythos. [...] Kultischer Bericht und rituelle Darstellung aktualisieren seine Wahrheit. Sie versetzt uns zurück in jene Zeit der Ursprünge - zum Quell von Sein, Kraft und Heil. So werden Mensch und Gemeinschaft periodisch erneuert und reintegriert."

Hans Thomas Hakl (2005, S. 20) bezieht sich in einem Beitrag in der Sezession ebenfalls auf die „Integrale Tradition“ und die Idee einer ewigen Philosophie. Diese sei ,keine Erfindung von Menschen, sondern ist uns sozusagen von, göttlicher' Seite übergeben worden und wir können nur versuchen, sie möglichst ,rein ' zu erkennen und dann weiterzutragen." Der Traditionalismus ist anschlussfähig für konservative Argumentationen, weil er überzeitliche Hierarchien legitimiert und die Ausdifferenzierung der Gesellschaft in der Moderne als Abkehr von einer ontologischen Wahrheit beklagt: „Da sie ,göttliche“ Herkunft beansprucht, ist sie letzte Instanz, kann nicht in Frage gestellt werden, ändert sich nicht und bildet die absolute Norm, nach der sich alles zu richten hat. Sie steht jenseits alles Menschlichen und jenseits alles Zeitlichen. In diesem Sinne ist sie ewig. Die moderne Welt in Form der westlichen Zivilisation und Technik, die auf rein materiellen, chemisch-physikalischen Grundlagen beruht, wird als das genaue Gegenteil dieser Tradition angesehen." (ebd, S. 20f.). Da der Mensch nach traditionaler Auffassung von ,zweifacher Natur“ sei, könne er durch Initiation, d.h. Askese oder heroische Taten, ,Zugang zur Transzendenz“ (ebd, S. 22) erlangen. Martin Lichtmesz (2015, S. 10) schreibt sich ebenfalls in die traditionalistische Vorstellungswelt ein, indem er Religion auf ein Moment der Überwältigung zurückführt und der „Machbarkeit“ der Religion eine Absage erteilt: „Was auch immer aus einer Religion in der Folge in sozialer, institutioneller und politischer Hinsicht wird, an ihrem Anfang stehen wohl immer Einzelne, Solitäre, die vom Brand des Dornbusches überwältigt werden.“

Die Rückführung der Religion auf einen transzendenten Kern hat in der Konservatismusforschung eine Entsprechung. So setzt Panajotis Kondylis (1986, S. 65; vgl. Lenk 1989, S. 28) das konservative Denken mit der Adelsgesellschaft der societas civilis und ihrer Rechtsvorstellung, Recht könne nicht gemacht werden, sondern sei Ausdruck einer ewigen göttlichen Ordnung, gleich. Der Niedergang der ständischen Gesellschaft machte diese Vorstellungen jedoch zu einem Anachronismus, weshalb der moderne Konservatismus mit neuen politischen und juristischen Legitimationsnarrativen zugleich andere Bezüge auf die Religion entwickeln musste, wie Philippe Bénéton (2017, S. 958) im „dictionnaire du conservatisme“ schreibt: „La religion est une composante essentielle de la tradition. Les conservateurs traditionalistes ne sont pas tous des croyants ou des croyants fervents mais, tous, ils insistent sur la fonction 
sociale de la religion. L'Église est une autorité, maitresse d'ordre et gardienne de la tradition, elle est une communauté forte de ses rituels, de ses cérémonies et de ses fêtes. “5 Die Ursprünge dieser exoterischen, d. h. funktionalistischen Religionsbezüge liegen im nachrevolutionären Frankreich.

\subsubsection{Exoterische Religionsbezüge: Vom Nutzen der Religion}

In exoterischen Religionsbezügen wird vor allem die Funktion der Religion als integrierende Sozialtechnik hervorgehoben, mit deren Hilfe Gesellschaften in Zeiten von ontologischer Ungewissheit und Krise stabilisiert werden können. Wie dem modernen Konservatismus geht ihr die protosoziologische Erfahrung einer Entzauberung der Welt voraus, auf die das rechte Denken mit dem Programm einer Wiederverzauberung antwortet. So fordert etwa der völkische AfD-Politiker Björn Höcke in seiner Programmschrift „Nie zweimal in denselben Fluss“: „Es geht nicht nur darum, ein Gemeinwesen gut zu organisieren. Es geht auch um die Wiederverzauberung der Welt.“ (Höcke 2018, S. 163).

Exemplarisch lässt sich dieses Programm an den französischen Gegenrevolutionären L.G.A de Bonald und Joseph de Maistre skizzieren, die die Religion ihrer theologischen Bezüge weitgehend entkleideten, um sie politisch zu funktionalisieren. Für beide war nicht die Abkehr von der theologischen Transzendenz das Fanal der bürgerlichen Revolution, sondern der Verlust eines systematischen Einheitsprinzips, das nun politisch neu gestiftet werden musste. Wie Robert Spaemann (1998, S. 183) in seiner Dissertation über die Protosoziologie Bonalds ausführt, wird der Begriff Gottes „bei ihm ausschließlich von seiner gesellschaftlichen Funktion her gewonnen“. Ähnliches gilt für Maistre, dessen Denken ,die nahezu vollständige Entsubstanzialisierung aller Begriffe der Tradition zugunsten ihrer machtpolitischen Instrumentalisierbarkeit“" (Heidemann 2020, S. 90) zur Folge hatte und in politischen Handlungsanweisungen mündete: „Will man ... etwas erhalten, so weihe man es.“ (Maistre, zit. n. Greiffenhagen 1986, S. 102).

Bonald und Maistre gehören zu den Begründern des französischen Konservatismus, erfuhren aber auch durch Henri de Saint-Simon und seinen Sekretär Auguste Comte eine intensive Rezeption in der französischen Soziologie, die sich bis zu den religionsfunktionalistischen Betrachtungen Émile Durkheims nachzeichnen lässt (vgl. Homann 1997, S. 255ff., 289ff.). Für die Entwicklung des rechten Denkens in der Dritten Französischen Republik sind zudem Georges Sorels Theorie der Sozialen Mythen und Charles Maurras' Konzeption des „Integralen Nationalismus“ prägend, die beide an den funktionalistischen Impuls anknüpften und ihn für moderne Massenbewegungen und den aufkommenden Nationalismus anschlussfähig machten. Carl Schmitt (1934, S. 71) schöpfte aus den Ideen Bonalds und Maistres seine Politische Theologie und begründete den Dezisionismus mit einem Verweis auf Maistre und die Effizienz klarer Autoritätsverhältnisse: „Notre intérêt n'est point,

\footnotetext{
5 „Religion ist ein wesentlicher Bestandteil der Tradition. Nicht alle traditionalistischen Konservativen sind gläubig oder strenggläubig, aber sie alle bestehen auf der sozialen Funktion der Religion. Die Kirche ist eine Autorität, Herrin der Ordnung und Hüterin der Tradition, eine starke Gemeinschaft mit eigenen Ritualen, Zeremonien und Festen.“.
} 
qu'une question soit decidée de telle ou telle manière, mais qu'elle le soit sans retard et sans appel." 6

Religion ist in den exoterischen Bezügen eine idealtypische Institution, wie sie sich Arnold Gehlen (2016, S. 65ff.) - mit Verweis auf Georges Sorels „De l'utilité du pragmatisme“ - zur Entlastung des menschlichen Mängelwesens vorgestellt hat. Auch sein Adept Karlheinz Weißmann (2005, S. 12) weist in der Sezession regelmäßig auf den „Nutzen der Religion“ hin: „Es liegt auf der Hand, daß sich die Nützlichkeit der Religion in diesem Fall aus ihrer Verbindlichkeit erklärt.“ (Weißmann 2005, S. 12). Dabei geht es ,im Kern um das Schwinden von Sinnressourcen und die Sorge, daß nur die Religion sich eigne, diesem Abbau Einhalt zu gebieten“ (Weißmann 2005, S. 9). Doch im Gegensatz zu Lichtmesz und Hakl sucht Weißmann (2003, S. 3) nicht nach einer spirituellen Transzendenz, sondern sieht sein Heil in der Kontinuität der Liturgie: „Für die Rechte ist die Hierarchie schön und mit ihr der liturgische Ausdruck." Sein Glauben ist instrumentell und im Diesseits der Kultur verankert, deren Dynamik er sistieren will: „Das erste Kriterium für Lebensdienlichkeit ist das Vermögen, Dauer zu schaffen. Die Rechte hat im Laufe ihrer Entwicklung ganz verschiedene Größen - die Kirche, die Krone, die Stände, das Volk - als Garanten der Dauer angesehen und ihnen Ewigkeit zugesprochen, aber im Grunde nie vergessen, daß diese äußeren Gestalten endlich sind und unter Umständen eine ,konservative Revolution“ nötig sein kann.“ (Weißmann 2003, S. 6).

\subsection{Apokalyptische Diskurspraxis}

Diese „konservative Revolution“ steht allerdings vor einem logischen „Dilemma“ (Greiffenhagen 1986). Das analytische Fundament der exoterischen Religiosität basiert auf Voluntarismus und der Reflexion der Kontingenz weltlicher Institutionen. Neurechte Argumentationen legitimieren sich jedoch zugleich durch den Verweis auf ontologische und anthropologische Figuren, die in eine esoterische Religiosität eingebettet sind. Wie apokalyptische Narrative stehen sie also im ,,pragmatischen Spannungsfeld zwischen Ideen und Interessen“ (Nagel 2008a, S. 134).

Neurechten Theoretikern wie Alain de Benoist, dem Doyen der französischen Nouvelle Droite, ist dieses Dilemma bewusst. In seiner Anthologie „Aus rechter Sicht“ heißt es: „Es gibt kein Absolutes. Ohne Absolutes aber, ohne etwas, das uns in unseren wesentlichsten Handlungen übersteigt und antreibt, können wir jedoch nicht leben. Kein Mensch entgeht der Problematik seiner Transzendenz. Zum ersten Male aber sind wir der Relativität der Normen und ihrer Notwendigkeit zugleich bewußt.“ (de Benoist 1983, S. 183; Hervorhebung im Original) Als Lösung schlägt Benoist die Überwältigung der Masse durch eine charismatische Führerfigur vor, was man als Aufruf zu politischer Propaganda verstehen kann: „Daraus folgt, daß eine neue „Objektivität“ nur aus einer ,heroischen“ Subjektivität wird entstehen können: aus einer Subjektivität, die einige wenige bewußt als Norm und mit solcher Kraft behaupten werden, daß diese Behauptung allen als eine natürliche vorkommen

\footnotetext{
6 „Es geht nicht darum, dass irgendeine Angelegenheit so oder so entschieden wird, sondern dass das ohne Verzögerung und ohne Berufung geschieht.“.
} 
wird.“ Diese Forderung gleicht der „Doppelstruktur“ (Brokoff 2001, S. 24) der apokalyptischen Sprechsituation, die sich durch den Verweis auf eine transzendente Wahrheit zugleich selbst ermächtigt.

Esoterische und exoterische Religionsbezüge im rechten Denken unterscheiden sich in ihren theoretischen Bezügen und Begründungsfiguren. Dennoch sind die politischen Forderungen, die sich daraus ergeben, ähnlich. Sowohl Benoist als auch Hakl fordern heroische Taten - der eine zur Stiftung, der andere zur Anerkennung einer höheren Instanz. Wie in den folgenden Fallbeispielen gezeigt wird, konvergieren diese Forderungen in einer apokalyptischen Diskurspraxis.

\subsubsection{Der Große Austausch}

Die Erzählung vom „Großen Austausch“ ist aktuell eines der erfolgreichsten Narrative der Neuen Rechten. Sie geht auf den französischen Schriftsteller Renaud Camus (2016, S. 161) zurück, der mit dem Schlagwort einen vermeintlichen Prozess der „Auflösung der Völker und der Zivilisation“ durch demografische (Migration) und kulturelle (Liberalismus) Faktoren beschreibt.

Für Camus (2016, S. 61f.) ist der „Große Austausch“ vor allem eine kulturpessimistische Dekadenzerzählung, die Säkularisierung, Demokratisierung, Individualisierung und Globalisierung denunziert. Der Idee einer Verschwörung globaler Eliten steht er eher skeptisch gegenüber. Durch die rechtsextreme „Identitäre Bewegung“ wurde Camus' Schlagwort erheblich popularisiert und auf konkrete Feindbilder zugespitzt, wie Martin Sellner (2016, S. 190) in einem Nachwort zu Camus schreibt: „Ein guter metapolitischer Begriff muß viele theoretische Überlegungen auf den Punkt bringen und dennoch klar verständlich sein. Er muß die richtigen Bilder evozieren, eine klare Erklärung des Geschehens (und das richtige Feindbild!) vermitteln. Er muß in sich eine ,Frage', eine Problemstellung, enthalten die als Lösung und Bewältiger die eigene Bewegung auf den Plan ruft. Kurz: Der Begriff muß in der Lage sein, die metapolitische Debatte zu überwölben. Das heißt: sich als Überbegriff für viele andere zu etablieren. Er muß zum Verständnishorizont und zur Metaerzählung werden. All diese theoretischen Fragen bewegten uns in der Identitären Bewegung, als wir mit der Kampagne zum ,Großen Austausch“ das von Renaud Camus geprägte Schlagwort vom grand remplacement erstmals in den deutschen Sprachraum einführten." Sellners metadiskursiver Kommentar zeigt deutlich, wie kalkuliert die Neue Rechte bei ihren Begriffsschöpfungen vorgeht und wie bewusst von ihr auf rhetorische Überwältigungsmittel zurückgegriffen wird.

Die metapolitische Erzählung der Identitären Bewegung ist durch eine doppelte Dichotomie geprägt, die die von Salzborn (2015, S. 290ff.) gezeigte Unterscheidung der drei Weltreligionen im neurechten Denken als das „Eigene“, das „Fremde“ und das „Andere“ variiert. Dem rechtspopulistischen Referenzobjekt „Wir, das Volk“" wird auf einer kategorialen Achse von innen und außen das Feindobjekt der „fremden Invasoren“ gegenübergestellt. Eine weitere Kampflinie verläuft auf einer kategorialen Achse von unten und oben zwischen „dem Volk“ und „den Eliten“. Die Funktion dieser doppelten Dichotomie wird von Sellner als „Problemstellung“ bezeichnet, die „eigene Bewegung“ in katechontischer Tradition als Bewältiger auf den Plan gerufen. Wenige Zeilen nach seinen metadiskursiven Überlegungen prä- 
sentiert Sellner (2016, S. 192) dann Camus' Dekadenzdiagnose als apokalyptisches Verschwörungsnarrativ: ,Wir wissen genau, daß die Masseneinwanderung Teil eines globalen Zerstörungsfeldzugs gegen alle Völker und Kulturen ist. Wir wissen genau, daß es die eigene Dekadenz und der liberalistische Werteverfall sind, die Europa erst sturmreif für die Invasion der Fremden gemacht haben. Wir wissen vor allem, daß der eigentliche ,Feind“ im eigenen Land sitzt, daß unsere Eliten, die uns fortgesetzt verraten, sowie unsere Intelligenz, die sich im Ethnomasochismus suhlt, die eigentlichen Urheber der Misere sind.“

Auf der Website der Identitären Bewegung (o.J.) ist noch deutlicher nachzuvollziehen, dass die Struktur dieser Erzählung der Dramaturgie der inversen Apokalypse gleicht und in der Forderung nach ,,politischen Gegenmaßnahmen“ auf die Figur des Katechon rekurriert. Das Stichwort „Großer Austausch“ wird dort definiert als „Prozess, durch den die heimisch angestammte Bevölkerung durch außereuropäische Einwanderer verdrängt und ausgetauscht wird. Wir befinden uns in ganz Europa in einer demographischen Krise, wonach unsere Völker durch sinkende Geburtenraten bei gleichzeitigem Wachstum islamischer Parallelgesellschaften und Masseneinwanderung zur Minderheit in den eigenen Ländern wird und in wenigen Jahrzehnten völlig verschwunden sein könnte, sofern keine politischen Gegenmaßnahmen eingeleitet werden."

Der apokalyptische Dualismus von Transzendenz und Immanenz wird in diesem Narrativ in eine politische Feindbestimmung transformiert. Es droht zwar kein Weltuntergang, aber, vorangetrieben durch eine globale Elite, eine demografische Krise, die die europäische Kultur unwiederbringlich zerstöre. Dabei stehe der „Große Austausch“ als ,wahres Problem hinter allen Randphänomenen und Friktionen. Die multikulturelle Gesellschaft ist der Übergangszustand des Großen Austauschs.“ (Sellner 2016, S. 194).

Im gegenwärtigen Interregnum sieht sich die selbsternannte „Identitäre Generation" selbst in der Rolle des Katechon und stilisiert vergangene hellenistische und christliche Verteidigungs- und Eroberungsschlachten gegen persische und muslimisch-arabische Heere zu ihrer Symbolik. Zum Bildrepertoire der Identitären Bewegung gehören Rückgriffe auf die Schlacht bei den Thermopylen im Jahr 480 v.u.Z., die Schlacht von Tours und Poitiers im Jahr 732 und die christliche „Reconquista" der Iberischen Halbinsel ab 722. Alexander Schnickmann (2021, S. 157) hat in seiner Analyse der Identitären Bewegung darauf hingewiesen, dass die Neuauflage der „Reconquista“ durch die Identitäre Bewegung „Herrschaft, religiöse Zugehörigkeit und heilsgeschichtlichen Auftrag verbinde“ und ,ein sich wandelndes Deutungsmuster [ist], das vor allem, aber keineswegs ausschließlich, um die Wiederherstellung vergangener Reiche und Zeiten kreist“" (ebd., S. 156). Apokalyptische Motive flankieren dabei eine narrative Struktur, die Handlungsdruck suggeriert und eine heroische Subjektivität anruft. Die Kontingenz, die durch den Appell an Subjektivität geöffnet wird, wird durch die apokalyptische Rhetorik jedoch zugleich wieder narrativ geschlossen. Sie ist kein Selbstzweck, sondern wird als Vollstrecker eines höheren Auftrags konstruiert: „Heroismus als Weg zur Transzendenz“, heißt es dementsprechend in einem Bericht auf der Website der Identitären Bewegung (2020). 


\subsubsection{QAnon}

Das zweite Fallbeispiel ist ein relativ junges Narrativ, das nicht explizit im Umfeld der Neuen Rechten entstanden ist. Die Rezeption des Narrativs durch die Neue Rechte demonstriert aber die Anschlussfähigkeit der apokalyptischen Struktur als „diskursive Formation, die zu unterschiedlichen Zeiten in unterschiedlichen Funktionen [auftritt]“ (Schnickmann 2021, S. 156).

Bei QAnon handelt es sich um eine Verschwörungstheorie, die 2017 auf dem Imageboard 4chan entstanden ist und sich aus „QQ - der Abkürzung für ,Q-Clearance“, der höchsten Zugriffsstufe von US-Sicherheitsbehörden - sowie ,Anon“ - der Abkürzung für „Anonymous“ - zusammensetzt. Auf 4chan können User ohne Registrierung Beiträge verfassen, die dann unter dem Namen „Anonymous“ erscheinen. Bei einem dieser User soll es sich um eine Person aus den US-Sicherheitsbehörden mit Zugriff auf geheime Informationen handeln, die unmittelbaren Zugang zum damaligen US-Präsidenten Donald J. Trump habe und in der Onlinecommunity deshalb „QAnon“ - oder kurz „Q“ - genannt wird. Q postet regelmäßig kryptische Beiträge, die andere User entschlüsseln sollen. Im Zentrum dieser Beiträge steht eine strukturell antisemitische Verschwörungstheorie, ${ }^{7}$ derzufolge sich eine globale Elite von pädophilen Satanisten und ein „Deep State“ gegen die Bevölkerung verschworen haben. Diese Elite entführe und foltere Kinder, um aus ihrem Blut das verjüngende Hormon Adrenochrom zu gewinnen. Doch Rettung naht, denn Donald Trump kämpfe als einsamer Rächer gegen die globale Elite und den „Deep State“, mit dem Ziel, ihr Machwerk zu beenden.

Die dualistische Struktur und das akute Bedrohungsszenario sind auch in diesem Narrativ evident. Für die Anhänger:innen der Verschwörungstheorie ist Donald Trump der Katechon, der den Sieg der globalen Elite verzögert. Entsprechend wurde die US-Präsidentschaftswahl 2020 von Q-Anhänger:innen zur Schicksalswahl stilisiert. Für Trump und sein politisches Umfeld ist die Verschwörungstheorie äuBerst funktional, denn sie liefert eine leicht zu kommunizierende und an bekannte kulturelle Muster anschließende Blaupause für politische Polarisierung. Inzwischen hat sie eine erschreckende Mobilisierungskraft, wie nicht zuletzt die Stürmung des Kapitols von Washington, D.C. im Januar 2021 gezeigt hat.

In Deutschland sind Bezüge zu QAnon vor allem im Umfeld der sogenannten Querdenker-Bewegung zu finden. Ein Telegram-Beitrag des einflussreichen Verschwörungstheoretikers und Youtubers Oliver Janich (zit. nach Sommerfeld 2020), der auf dem Blog der neurechten Sezession aufgegriffen wurde, zeigt exemplarisch die Verschränkung von apokalyptischer Symbolik und ihrer Funktion, Polarisierung und Handlungsdruck zu erzeugen: ,Ich werde mir die Satanisten-Leugner demnächst vornehmen. Einen nach dem anderen, damit ein für alle mal klar ist, wer auf unserer Seite ist und wer auf deren. Wir sind im Endkampf gut gegen böse. Wenn sie die zweite Welle und den Bioterrorangriff inszenieren und damit durchkommen, ist es vorbei." Charakteristisch ist auch in diesem Fragment die zugespitzte Entschei-

\footnotetext{
7 Im Mittelalter wurde den Juden vorgeworfen, Christenkinder zu entführen und zu martern, um aus ihrem Blut ein rituelles Gebäck herzustellen. Die narrativen Parallelen der QAnon-Verschwörungstheorie zu dieser antijüdischen Ritualmordlegende sind frappierend.
} 
dungssituation, die keine Äquidistanz zulässt. Das dramaturgische Muster läuft auf einen finalen Punkt zu, den es zu verhindern gilt.

Martin Sellner (2020) von der Identitären Bewegung führt in einem Beitrag für die Septemberausgabe der rechtsextremen Zeitschrift Compact, die unter dem äquivoken Titel „Q“ den Querdenkern gewidmet ist, die gleichen Motive an: „Im aktuellen Konflikt geht es daher nicht nur um die Gesundheitspolitik in Deutschland, sondern um viel mehr. Er steht symbolisch für die Gigantomachie, den seit einem Jahrhundert wütenden Endkampf zwischen Patrioten und Globalisten." Und auch CompactChefredakteur Jürgen Elsässer greift im Editorial der gleichen Zeitschrift fast idealtypisch auf eine apokalyptische Narration zurück (vgl. Schilk 2017, S. 131ff.), indem Autokraten wie Aljaksandr Lukaschenka, Donald Trump und Jair Bolsonaro als Katechonten gegen die drohende „Corona-Diktatur“ des ,westlichen Establishments“ aufgestellt und im warnenden Ton eine Entscheidung zwischen Verhängnis oder Neuanfang gefordert wird: „Nach dem Vorbild von Lukaschenko sollen auch Trump und Bolsonaro gestürzt werden - dann würde sich der Eiserne Vorhang des neuen Totalitarismus über die ganze Welt senken. Was aber, wenn es uns noch vorher gelingt, Merkel zu stürzen?“`(Elsässer 2020).

Im Gegensatz zur Erzählung des Großen Austauschs ist der religiöse Ursprung der apokalyptischen Metaphorik in der QAnon-Verschwörungstheorie noch deutlich zu vernehmen. Durch die Assoziation von „globalen Eliten“ und satanistischen Praktiken wird das Feindbild zum „Antichristen“ stilisiert. Es droht demnach nicht der Untergang einer lokalen Kultur, sondern nichts weniger als der letzte Kampf zwischen Gut und Böse, eine finale Entscheidung zwischen patriotischem Neuanfang oder neuem Totalitarismus auf der ganzen Welt. Die Figur „Q“ fungiert dabei als Prophet, der drängende Handlungsanweisungen vor dem Hintergrund einer stets drohenden, aber letztlich doch nie stattfindenden Apokalypse ausgibt. Die Neuen Rechten inszenieren sich selbst als „Aufhalter“ einer umfassenden Gegenwartskrise, die sie mit rhetorischen und narrativen Mitteln unentwegt beschwören.

\subsubsection{Die Diskursmacht des Katechon}

Beide Beispiele zeigen, was Nagel et al. (2008, S. 308) als „Diskursmacht“ der Apokalypse bezeichnen. Die Neue Rechte greift bewusst auf anschlussfähige Krisendeutungen zurück, um sich selbst als Bewältiger zu empfehlen. Apokalyptische Motive werden dabei als Textstrategie genutzt, um Geltungsansprüche zu begründen und Handlungsdruck zu erzeugen. Wie Martin Sellner (2016, S. 192) konstatiert, sei der Rückbezug auf die Apokalyptik jedoch nicht ausschließlich instrumentell: „,Der Begriff [Großer Austausch] vereint in sich alle propagandistischen und strategischen Anforderungen und befindet sich voll im Einklang mit der identitären Theorie."

Zwischen der inversen Form der Apokalypse und rechten Krisennarrativen bestehen Strukturähnlichkeiten, die wissenssoziologisch aus dem sozialen Entstehungskontext apokalyptischer und konservativer Texte erklärt werden können. Beides sind Deutungsmuster für reale Krisenerfahrungen, die einen Verlust von lebensweltlichen Sicherheiten und Selbstverständlichkeiten artikulieren und auf die Restabilisierung von Ordnungsstrukturen drängen. Es geht also um die Bearbeitung von Kontingenz durch ihre Kosmisierung in rigiden Sinnstrukturen (vgl. Luckmann 1985). Der klas- 
sische apokalyptische Dreischritt von Immanenz - Untergang - Transzendenz wird in rechten Krisennarrativen invertiert und verweltlicht, indem unter Rückgriff auf die katechontische Form der Apokalyptik heroische Subjekte auf den Plan gerufen werden, deren Regime sich die unheroische Masse unterwerfen soll.

\section{Fazit}

In meinem Beitrag habe ich das Verhältnis der extremen Rechten zur Religion untersucht. Dabei ist deutlich geworden, dass ein eindimensionaler Religionsbegriff, der Religion entweder auf ihren Glaubensinhalt oder auf ihre sozialintegrative Funktion reduziert, dem ambivalenten Charakter der untersuchten Phänomene nicht gerecht wird. Die analytische Unterscheidung zwischen gegenstandsspezifischen, kontextuellen und dekonstruktivistischen Religionsbegriffen (vgl. Pollack 2018) ist aber hilfreich, um Facetten des Konservatismus, des Rechtspopulismus und der Neuen Rechten zu erschließen.

Die allen drei Phänomenen zugrundeliegenden Menschen- und Gesellschaftsbilder basieren auf einer sozialen Ontologie, deren Vorstellung von überzeitlich-transzendenten Ordnungen und Hierarchien, denen sich der Mensch unterwerfen müsse, einen religiösen Charakter hat. Hier schließen esoterische Religionsbezüge an, bei denen Transzendenzbehauptungen im Fokus stehen.

Als genuin moderne politische Hegemonieprojekte verfolgen der Konservatismus, der Rechtspopulismus und die Neue Rechte zugleich das Programm einer Wiederverzauberung der Welt, durch das weltliche Institutionen und Autoritäten gegen Kritik immunisiert werden sollen. Dieses Programm knüpft an exoterische Religionsbezüge an, in denen die Religion primär in ihrer sozialen Funktion der Kohäsions- und Legitimitätsstiftung verstanden wird.

Gegen ihre politischen Gegner:innen mobilisieren Konservative, Rechtspopulist:innen und Neue Rechte schließlich apokalyptische Krisennarrative, die sich durch eine spezifische „Diskursmacht“ auszeichnen und religiöse Deutungsmuster in die Ebene des Politischen übersetzen. Apokalyptische Motive eignen sich für eine polarisierende Kommunikation und die Erzeugung von Handlungsdruck, der politisch kapitalisiert werden kann. Die apokalyptische Textstruktur ist aber auch das Ergebnis einer „Enttäuschungsverarbeitung“ (Lenk 1989, S. 50), die sie als Erfahrungskontext mit dem modernen Konservatismus teilt.

Eine vergleichbare apokalyptische Struktur ließe sich indes auch an anderen Textgenres aufzeigen. So sind etwa kulturkritische und populistische Zeitdiagnosen ähnlich dichotom konzipiert und in einer narrativen Form verfasst (vgl. Osrecki 2018). Der „kulturelle Code“ (vgl. Volkov 2000) des Antisemitismus knüpft strukturell an die normative Binarität von ,böser“ Immanenz und ,guter“ Transzendenz an. Die Verschwörungstheorien der sogenannten Reichsbürger (vgl. Begrich und Speit 2017) stehen in einer katechontischen Tradition, die die politischen Institutionen der Gegenwart delegitimiert und zu einer Verteidigung eines vermeintlich wahrhaftigeren Reiches aufruft, dessen Legitimität aus einer mythischen Vergangenheit geschöpft wird. Mit Heuristiken der Apokalyptikforschung lässt sich nicht nur die Struktur und Funktion derartiger Krisennarrative analysieren, vielmehr können auch 


\section{ihre Anschlussmöglichkeiten an andere Diskursstränge sowie Querverbindungen zu anderen Diskursfeldern rekonstruiert werden.}

Funding Open Access funding enabled and organized by Projekt DEAL.

Open Access Dieser Artikel wird unter der Creative Commons Namensnennung 4.0 International Lizenz veröffentlicht, welche die Nutzung, Vervielfältigung, Bearbeitung, Verbreitung und Wiedergabe in jeglichem Medium und Format erlaubt, sofern Sie den/die ursprünglichen Autor(en) und die Quelle ordnungsgemäß nennen, einen Link zur Creative Commons Lizenz beifügen und angeben, ob Änderungen vorgenommen wurden.

Die in diesem Artikel enthaltenen Bilder und sonstiges Drittmaterial unterliegen ebenfalls der genannten Creative Commons Lizenz, sofern sich aus der Abbildungslegende nichts anderes ergibt. Sofern das betreffende Material nicht unter der genannten Creative Commons Lizenz steht und die betreffende Handlung nicht nach gesetzlichen Vorschriften erlaubt ist, ist für die oben aufgeführten Weiterverwendungen des Materials die Einwilligung des jeweiligen Rechteinhabers einzuholen.

Weitere Details zur Lizenz entnehmen Sie bitte der Lizenzinformation auf http://creativecommons.org/ licenses/by/4.0/deed.de.

\section{Literatur}

\section{Quellen}

Bénéton, Philippe. 2017. Tradition, Traditionalisme. In Le dictionnaire du conservatisme, Hrsg. Frédéric Rouvillois, Oliver Dard, und Christoph Boutin, 956-960. Paris: Cerf.

de Benoist, Alain. 1983. Aus rechter Sicht. Tübingen: Grabert.

Boutin, Christophe. 2017. Tradition (pensée de la). In Le dictionnaire du conservatisme, Hrsg. Frédéric Rouvillois, Oliver Dard, und Christoph Boutin, 953-956. Paris: Cerf.

Camus, Renaud. 2016. Revolte gegen den Großen Austausch. Schnellroda: Antaios.

Cortés, Donoso. 1933. Der Staat Gottes. Eine katholische Geschichtsphilosophie. Karlsruhe: Badenia.

Eliade, Mircea. 1957. Das Heilige und das Profane. Vom Wesen des Religiösen. Hamburg: Rowohlt.

Elsässer, Jürgen. 2020. Corona-Geier über Minsk. Compact 9/2020:3.

Guillaud, Frédéric. 2017. Religion. In Le dictionnaire du conservatisme, Hrsg. Frédéric Rouvillois, Oliver Dard, und Christoph Boutin, 798-803. Paris: Cerf.

Hakl, Hans Thomas. 2005. Die Integrale Tradition. Sezession 11:20-26.

Höcke, Björn. 2018. Nie zweimal in denselben Fluss. Lüdinghausen: Manuscriptum.

Identitäre Bewegung. 2020. Spartas Mauern sind seine Männer. https://www.identitaere-bewegung.de/ blog/spartas-mauern-sind-seine-maenner/. Zugegriffen: 12. Jan. 2021.

Identitäre Bewegung. o.J. Was meint der Begriff „Großer Austausch“ und wer ist schuld daran? https:// www.identitaere-bewegung.de/faq/was-meint-der-begriff-grosser-austausch-und-wer-ist-schulddaran/. Zugegriffen: 14. Jan. 2021.

Kaltenbrunner, Gerd-Klaus. 1977. Konservative Apokalypse. In Frankfurter Allgemeine Zeitung vom 2. September 1977: 23.

Lichtmesz, Martin. 2015. Sind Religionen machbar? Sezession 68:16-20.

Saur, Wolfgang. 2010. Das Heilige und das Profane. In Schlüsselwerke, Bd. 2, Hrsg. Erik Lehnert, Karlheinz Weißmann, 116-117. Schnellroda: Antaios.

Schmitt, Carl. 1934. Politische Theologie. München, Leipzig: Duncker \& Humblot.

Sellner, Martin. 2016. Der Große Austausch in Deutschland und Österreich: Theorie und Praxis. In Revolte gegen den Großen Austausch, Hrsg. Renaud Camus, 189-221. Schnellroda: Antaios.

Sellner, Martin. 2020. Corona-Rebellen und Patrioten. Compact 9/2020:20.

Sommerfeld, Caroline. 2020. Politischer Gnostizismus. https://sezession.de/62896/politischer-gnostizismus. Zugegriffen: 12. Jan. 2021.

Weißmann, Karlheinz. 2003. Das rechte Prinzip. Sezession 3:2-6.

Weißmann, Karlheinz. 2005. Vom Nutzen der Religion. Sezession 11:8-12. 
Weißmann, Karlheinz. 2009a. Katechon. In Leitbegriffe Staatspolitisches Handbuch, Bd. 1, Hrsg. Erik Lehnert, Karlheinz Weißmann, 86-87. Schnellroda: Antaios.

Weißmann, Karlheinz. 2009b. Religion. In Leitbegriffe Staatspolitisches Handbuch, Bd. 1, Hrsg. Erik Lehnert, Karlheinz Weißmann, 132-133. Schnellroda: Antaios.

\section{Literatur}

Ackermann, Jan, Katharina Behne, Felix Buchta, Marc Drobot, und Philipp Knopp. 2015. Metamorphosen des Extremismusbegriffes. Diskursanalytische Untersuchungen zur Dynamik einer funktionalen Unzulänglichkeit. Wiesbaden: Springer VS.

Allport, Gordon W. 1966. Religious context of prejudice. Journal for the Scientific Study of Religion 5(3):447-457. https://doi.org/10.2307/1384172.

Althoff, Andrea. 2018. Right-wing populism and religion in Germany: conservative Christians and the Alternative for Germany (AfD). Zeitschrift für Religion, Gesellschaft und Politik 2(2):335-363.

Bednarz, Liane. 2020. Rechte Christentumsdiskurse - ein Überblick. In Einsprüche. Studien zur Vereinnahmung von Theologie durch die extreme Rechte, 8-22. : Bundesarbeitsgemeinschaft Kirche + Rechtsextremismus.

Bednarz, Liane, und Steven Schäller. 2021. Rechts und konservativ ist nicht dasselbe. Ein Gespräch über Christen in der Politik. In Die neue Mitte? Ideologie und Praxis der populistischen und extremen Rechten, Hrsg. Johannes Schütz, Steven Schäller, und Raj Kollmorgen, 93-108. Köln: Böhlau. https:// doi.org/10.7788/9783412522292.47.

Begrich, David, und Andreas Speit. 2017. „Heiliges Deutsches Reich“. Reichsidee und Reichsideologie der extremen Rechten. In Reichsbürger. Die unterschätzte Gefahr, Hrsg. Andreas Speit, 22-40. Berlin: Christoph Links.

Berendsen, Eva, Katharina Rhein, und Tom Uhlig. 2019. Extrem Unbrauchbar. Über Gleichsetzungen von links und rechts. Berlin: Verbrecher Verlag.

von Beyme, Klaus. 2013. Konservatismus. Theorien des Konservatismus und Rechtsextremismus im Zeitalter der Ideologien 1789-1945. Wiesbaden: Springer VS.

Bizeul, Yves. 2018. Die religiöse Dimension im Denken und Handeln der französischen Rechtspopulisten. Zeitschrift für Religion, Gesellschaft und Politik 2(2):365-385.

Bobbio, Norberto. 1994. Gründe und Bedeutungen einer politischen Unterscheidung. Berlin: Wagenbach.

Botsch, Gideon. 2020. Die ,Juden in der AfD “ und der Antisemitismus. Mitteilungen der Emil Julius Gumbel Forschungsstelle. Moses Mendelssohn Zentrum für europäisch-jüdische Studien, Bd. 7, 1-15.

Brokoff, Jürgen. 2001. Die Apokalypse in der Weimarer Republik. München: W. Fink.

Chemin, Ariane. 2017. La seconde jeunesse d'Alain de Benoist. In Le Monde vom 11. Januar 2017: 13.

Dubiel, Helmut. 1986. Das Gespenst des Populismus. In Populismus und Aufklärung, Hrsg. Helmut Dubiel, 33-50. Frankfurt am Main: Suhrkamp.

Elm, Ludwig (Hrsg.). 1986. Konservatismus heute. Internationale Entwicklungstrends konservativer Politik und Gesellschaftstheorien in den achtziger Jahren. Köln: Pahl-Rugenstein.

Faber, Richard (Hrsg.). 1997. Politische Religion - religiöse Politik. Würzburg: Königshausen und Neumann.

Garfinkel, Harold. 1967. Studies in ethnomethodology. New Jersey: Prentice-Hall.

Gehlen, Arnold. 1963. Über die Geburt der Freiheit aus der Entfremdung. In Studien zur Anthropologie und Soziologie, Hrsg. Arnold Gehlen, 232-246. Neuwied: Luchterhand.

Gehlen, Arnold. 2016. Der Mensch. Seine Natur und seine Stellung in der Welt. Frankfurt am Main: Klostermann.

Gerhards, Claudia. 1999. Apokalypse und Moderne. Alfred Kubins „Die andere Seite“ und Ernst Jüngers Frühwerk. Würzburg: Königshausen \& Neumann.

Gessenharter, Wolfgang. 1994. Kippt die Republik? Die Neue Rechte und ihre Unterstützung durch Politik und Medien. München: Knaur.

Greiffenhagen, Martin. 1986. Das Dilemma des Konservatismus in Deutschland. Frankfurt am Main: Suhrkamp.

Greß, Franz, Hans-Gerd Jaschke, und Klaus Schönekäs. 1990. Neue Rechte und Rechtsextremismus in Europa. Bundesrepublik, Frankreich, Großbritannien. Opladen: Westdeutscher Verlag.

Hacke, Jens. 2006. Philosophie der Bürgerlichkeit. Die liberalkonservative Begründung der Bundesrepublik. Göttingen: Vandenhoeck \& Ruprecht. 
Heidemann, Michael. 2020. „...damit der Mensch lernt, dass er nur ein Instrument ist...“ Elemente der Gegenaufklärung in der Souveränitätslehre Joseph de Maistres. Sans Phrase 16:70-90.

Hidalgo, Oliver. 2018. Religion, (Rechts-)Populismus und Demokratie - Versuch einer theoretischen Verhältnisbestimmung. Zeitschrift für Religion, Gesellschaft und Politik 2(2):167-192.

Hidalgo, Oliver, Philipp W. Hildmann, und Alexander Yendell. 2019. Religion und Rechtspopulismus. Argumentation Kompakt 3/2019. Hans-Seidel Stiftung. https://www.hss.de/download/publications/ Argu_Kompakt_2019-3_Religion.pdf. Zugegriffen: 12. Jan. 2021.

Homann, Heinz-Theo. 1997. Das funktionale Argument. Konzepte und Kritik funktionslogischer Religionsbegründung. Paderborn: F. Schöningh.

Keller, Reiner. 2008. Diskurse und Dispositive analysieren. Die Wissenssoziologische Diskursanalyse als Beitrag zu einer wissensanalytischen Profilierung der Diskursforschung. Historical Social Research 33(1):73-107.

Kondylis, Panajotis. 1986. Konservativismus. Geschichtlicher Gehalt und Untergang. Stuttgart: Klett-Cotta.

Korsch, Felix. 2020. Deutschland ist Abendland. In Das faschistische Jahrhundert. Neurechte Diskurse zu Abendland, Identität, Europa und Neoliberalismus, Hrsg. Friedrich Burschel, 39-110. Berlin: Verbrecher Verlag.

Koselleck, Reinhart. 1973. Kritik und Krise. Eine Studie zur Pathogenese der bürgerlichen Welt. Frankfurt am Main: Suhrkamp.

Kühnlein, Michael. 2019. konservativ?! Miniaturen aus Kultur, Politik und Wissenschaft. Berlin: Duncker \& Humblot.

Lenk, Kurt. 1989. Deutscher Konservatismus. Frankfurt am Main, New York: Campus.

Lenk, Kurt. 2005. Das Problem der Dekadenz seit Georges Sorel. In Völkische Bande. Dekadenz und Wiedergeburt - Analysen rechter Ideologie, Hrsg. Heiko Kauffmann, Helmut Kellershohn, und Paul Jobst, 49-63. Münster: Unrast.

Luckmann, Thomas. 1985. Über die Funktion der Religion. In Die religiöse Dimension der Gesellschaft. Religion und ihre Theorie, Hrsg. Peter Koslowski, 26-41. Tübingen: Mohr Siebeck.

Luhmann, Niklas. 1974. Der politische Code „konservativ“ und ,progressiv“ in systemtheoretischer Sicht. Zeitschrift für Politik 21(3):253-271.

Macherey, Pierre. 1992. Aux sources des „rapports sociaux“. Bonald, Saint-Simon, Guizot. Genèses. Sciences sociales et histoire 9:25-43.

Makropoulos, Michael. 1997. Modernität und Kontingenz. München: Fink.

Mannheim, Karl. 1984. Konservatismus. Ein Beitrag zur Soziologie des Wissens. Frankfurt am Main: Suhrkamp.

Maus, Heinz. 1956. Geschichte der Soziologie. In Handbuch der Soziologie, Hrsg. Werner Ziegenfuß, 1-120. Stuttgart: Ferdinand Enke Verlag.

Meier-Vieracker, Simon. 2020. Selbstlegitimation von Hass auf rechten Internetseiten. In Diskurs - ethisch, Hrsg. Heidrun D. Kämper, Ingo H. Warnke, 139-155. Bremen: Hempen.

Moffitt, Benjamin. 2016. The global rise of populism: performance, political style, and representation. Stanford: Stanford University Press.

Mouffe, Chantal. 2018. Für einen linken Populismus. Berlin: Suhrkamp.

Mudde, Cas. 2004. The Populist Zeitgeist. In Government and Opposition, Bd. 4, 542-563.

Müller, Jan-Werner. 2016. Was ist Populismus? Ein Essay. Berlin: Suhrkamp.

Nagel, Alexander-Kenneth. 2008a. Europa wider den Antichrist. Politische Apokalyptik zwischen Innovation und Institutionalisierung. Zeitschrift für Religionswissenschaft 16(2):133-156.

Nagel, Alexander-Kenneth. 2008b. Ordnung im Chaos - Zur Systematik apokalyptischer Deutung. In Apokalypse. Zur Soziologie und Geschichte religiöser Krisenrhetorik, Hrsg. Alexander-Kenneth Nagel, Bernd U. Schipper, und Ansgar Weymann, 49-72. Frankfurt am Main: Campus.

Nagel, Alexander-Kenneth. 2021. Corona und andere Weltuntergänge. Apokalyptische Krisenhermeneutik in der modernen Gesellschaft. Bielefeld: transcript.

Nagel, Alexander-Kenneth, Bernd U. Schipper, und Ansgar Weymann. 2008. Apokalypse - Zur religiösen Konstruktion gesellschaftlicher Krise. In Apokalypse. Zur Soziologie und Geschichte religiöser Krisenrhetorik, Hrsg. Alexander-Kenneth Nagel, Bernd U. Schipper, und Ansgar Weymann, 303-309. Frankfurt am Main: Campus.

Nisbet, Robert A. 1952. Conservatism and Sociology. American Journal of Sociology 58(2):167-175.

Osrecki, Fran. 2018. Die Geschichte der Gegenwartsdiagnostik in der deutschsprachigen Soziologie. In Handbuch Geschichte der deutschsprachigen Soziologie, Hrsg. Stephan Moebius, Andrea Ploder, 453-475. Wiesbaden: Springer VS. 
Pfahl-Traughber, Armin. 2017. Zeitschriftenporträt: Sezession. In Jahrbuch Extremismus \& Demokratie, Hrsg. Uwe Backes, Eckhard Jesse, 216-230. Baden-Baden: Nomos.

Pickel, Gert. 2018. Religion als Ressource für Rechtspopulismus? Zwischen Wahlverwandtschaften und Fremdzuschreibungen. Zeitschrift für Religion, Gesellschaft und Politik 2(2):277-312.

Pollack, Detlef. 2018. Probleme der Definition von Religion. In Handbuch Religionssoziologie, Hrsg. Detlef Pollack, Volkhard Krech, Olaf Müller, und Markus Hero, 17-50. Wiesbaden: Springer VS.

Priester, Karin. 2007. Populismus. Historische und aktuelle Erscheinungsformen. Frankfurt am Main: Campus.

Rebenstorf, Hilke. 2018. „Rechte“ Christen? - Empirische Analysen zur Affinität christlich-religiöser und rechtspopulistischer Positionen. Zeitschrift für Religion, Gesellschaft und Politik 2(2):313-333.

Reitz, Tilman. 2016. Das zerstreute Gemeinwesen. Politische Semantik im Zeitalter der Gesellschaft. Wiesbaden: Springer VS.

Reuter, Hans-Richard. 2018. Katechonten des Untergangs. Nation und Religion im Denken der deutschen Neuen Rechten. Berliner Theologische Zeitschrift 35(1):13-33.

Salzborn, Samuel. 2015. Religionsverständnisse im Rechtsextremismus. Eine Analyse am Beispiel des neurechten Theorieorgans Sezession. In Jahrbuch Öffentliche Sicherheit 2014/2015, Hrsg. van Ooyen, Möllers, 285-301. : Verlag für Polizeiwissenschaft.

Schilk, Felix. 2017. Souveränität statt Komplexität. Wie das Querfront-Magazin „Compact“ die politische Legitimationskrise der Gegenwart bearbeitet. Münster: Unrast.

Schipper, Bernd U. 2008. Apokalyptik und Apokalypse. Ein religionsgeschichtlicher Überblick. In Apokalypse. Zur Soziologie und Geschichte religiöser Krisenrhetorik, Hrsg. Alexander-Kenneth Nagel, Bernd U. Schipper, und Ansgar Weymann, 73-98. Frankfurt am Main: Campus.

Schnickmann, Alexander. 2021. Reich ohne König. Reconquista und Endspiel der Neuen Rechten. In Leben am Ende der Zeiten. Wissen, Praktiken und Zeitvorstellungen der Apokalypse, Hrsg. Berger, Louis Mathias, Hajo Raupach, und Alexander Schnickmann, 145-170. Frankfurt am Main: Campus.

Sedgwick, Mark. 2019. Gegen die moderne Welt. Die geheime Geistesgeschichte des 20. Jahrhunderts. Berlin: Matthes \& Seitz.

Spaemann, Robert. 1998. Der Ursprung der Soziologie aus dem Geist der Restauration. Studien über L. G. A. de Bonald. Stuttgart: Klett-Cotta.

Steber, Martina. 2017. Die Hüter der Begriffe. Politische Sprachen des Konservativen in Großbritannien und der Bundesrepublik Deutschland, 1945-1980. Oldenbourg: De Gruyter.

Umland, Andreas. 2019. Alexandr Dugin. Antiwestlertum und Kreuzzug gegen den Liberalismus. In Das alte Denken der Neuen Rechten. Die langen Linien der antiliberalen Revolte, Hrsg. Zentrum Liberale Moderne, 109-119.

Vierhaus, Rudolf. 1982. Konservativ, Konservatismus. In Geschichtliche Grundbegriffe. Historisches Lexikon zur politisch-sozialen Sprache in Deutschland, Bd. 3, Hrsg. Otto Brunner, Werner Conze, und Reinhart Koselleck, 531-565. Stuttgart: Klett-Cotta.

Voegelin, Eric. 1993. Die politischen Religionen. München: Fink.

Volkov, Shulamit. 2000. Antisemitismus als kultureller Code. Zehn Essays. München: Beck.

Vondung, Klaus. 1971. Magie und Manipulation. Ideologischer Kult und politische Religion des Nationalsozialismus. Göttingen: Vandenhoeck \& Ruprecht.

Vondung, Klaus. 1988. Die Apokalypse in Deutschland. München: Deutscher Taschenbuch Verlag.

Weiß, Volker. 2017. Die Autoritäre Revolte. Die NEUE RECHTE und der Untergang des Abendlandes. Stuttgart: Klett-Cotta.

Weymann, Ansgar. 2008. Gesellschaft und Apokalypse. In Apokalypse. Zur Soziologie und Geschichte religiöser Krisenrhetorik, Hrsg. Alexander-Kenneth Nagel, Bernd U. Schipper, und Ansgar Weymann, 13-48. Frankfurt am Main: Campus.

Wiedemann, Felix. 2016. Das Verhältnis der extremen Rechten zur Religion. In Handbuch Rechtsextremismus, Hrsg. Fabian Virchow, Martin Langebach, und Alexander Häusler, 511-523. Wiesbaden: Springer VS. 